\title{
Correlation Between Bulk and Surface Resistivity of Concrete
}

\author{
Pratanu Ghosh*, and Quang Tran
}

(Received April 2, 2014, Accepted November 4, 2014, Published online November 21, 2014)

\begin{abstract}
Electrical resistivity is an important physical property of portland cement concrete which is directly related to chloride induced corrosion process. This study examined the electrical surface resistivity (SR) and bulk electrical resistivity (BR) of concrete cylinders for various binary and ternary based high-performance concrete (HPC) mixtures from 7 to 161 days. Two different types of instruments were utilized for this investigation and they were 4 point Wenner probe meter for SR and Merlin conductivity tester for bulk resistivity measurements. Chronological development of electrical resistivity as well as correlation between two types of resistivity on several days was established for all concrete mixtures. The ratio of experimental surface resistance to bulk resistance and corresponding resistivity was computed and compared with theoretical values. Results depicted that bulk and SR are well correlated for different groups of HPC mixtures and these mixtures have attained higher range of electrical resistivity for both types of measurements. In addition, this study presents distribution of surface and bulk resistivity in different permeability classes as proposed by Florida Department of Transportation (FDOT) specification from 7 to 161 days. Furthermore, electrical resistivity data for several HPC mixtures and testing procedure provide multiple promising options for long lasting bridge decks against chloride induced corrosion due to its ease of implementation, repeatability, non-destructive nature, and low cost.
\end{abstract}

Keywords: surface resistivity, bulk resistivity, HPC, corrosion, conductivity.

\section{Introduction}

Chloride induced corrosion is one of the major problems in concrete bridge decks, pavements, and other marine structures. For this reason, electrical resistance against corrosion protection needs to be evaluated for repair and retrofit of concrete structures. As a result, since the last decade, there is growing demand to develop and implement electrical response techniques as a health monitoring tool for concrete structures.

Electrical resistivity is noninvasive and non-destructive and can evaluate microstructure of concrete, it can be related to the volume fraction of the pores, conductivity of the pore solution and can be utilized to predict the diffusion coefficients of chloride ions and water permeability (Christensen et al. 1994). Typically chloride resistance of concrete by electrical response is determined by the rapid chloride ion penetration (RCPT) according to ASTM C1202-05 standard. The total charge passed in coulomb in $6 \mathrm{~h}$ of RCPT is considered a relative measure and indication of the concrete's resistance to chloride ingress. One major limitation of the RCPT is the high current flow through permeable concrete mixtures results in a "joule effect". The increase in

Department of Civil and Environmental Engineering, California State University, Fullerton, Fullerton, USA. *Corresponding Author; E-mail: pghosh@fullerton.edu Copyright $($ The Author(s) 2014. This article is published with open access at Springerlink.com temperature effectively decreases the electrical resistance and encourages the electrical current to flow rapidly and produce more heat which further accelerates the current flow (Julio-Betancourt and Hooton 2004). However, the monitoring of the non-destructive methodology such as change of the electrical resistivity provides much more data about concrete properties in different conditions as a quality control tool in a simple way. One of the existing non-destructive methods of determination of concrete resistance to the chloride ion penetration is the surface electrical resistivity by Wenner 4-probe device. The FDOT has developed a method to standardize procedures for collection of resistivity readings (FDOT Standard 2004). Experimentation using the Wenner device on 529 samples was conducted by Kessler et al. (2005) at the FDOT to investigate whether resistivity can be used as a quality control measure in place of the RCPT. Tikalsky et al. (2011) completed a recent study on different binary and ternary based HPC mixtures electrical resistivity testing a 91 days and found that resistivity data is well correlated with RCPT data for different binary and ternary based HPC mixtures.

Previous research suggested that supplementary cementitious materials (SCMs) can be used as a partial cement replacement to increase the electrical resistivity of mortar and concrete (Katherine et al. 2010). Marriaga et al. (2010) studied the reliability of the RCPT and resistivity test on the basis of chloride resistance of ground granulated blast furnace slag (GGBFS) mixtures with different levels of cement replacements. They established that the electrical resistivity and the 
total charge passed is an indirect measure of the chloride penetration suitable for both ordinary portland cement (OPC) and GGBS mixtures. Icenogle et al. (2012) recently showed that the better precision of Wenner Probe resistivity meter from their experimental investigation of single laboratory and multi laboratory measurements and surface resistivity test shows lower variability than rapid chloride permeability test with different HPC mixtures. Paredes et al. (2012) conducted rigorous round robin program to document the repeatability and reproducibility of surface measurements data on 12 different PCC mixtures in several laboratories. Darren et al. (2011) established effectiveness of electrical resistivity technique for HPC to obtain a relationship with chloride diffusivity in order to evaluate the quality of the concrete. Their findings showed a high correlation coefficient in the range between 0.94-0.99, representing the suitability of using electrical resistivity technique to evaluate the quality control of high performance concrete and prediction of corrosion rate. Another possible method is to measure electrical resistance of concrete cylinder by using plate electrodes on the end of the sample (Polder et al. 2004; Newlands et al. 2008). This test can be performed by utilizing conductive medium and needs to be remembered that surface finish needs to be flat as much as possible for proper contact pressure and sponges were used between sample and plates to obtain better contact. Recently, Spragg et al. (2012) analyzed variability studies on 12 different cementitious mixtures for BR and SR and correlation was established at testing ages of 28, 56 and 91 days. Additionally, the effect of electrode resistance was discussed. It was noticed that the effect is not significant on high resistivity concrete.

Most of the previous study on electrical resistivity focused on measurement of a limited number of concrete mixtures over a shorter period of time. In this study, comprehensive investigation of bulk and surface electrical resistivity of thirty three different binary and ternary based HPC mixtures containing large numbers of supplementary materials have been conducted from 7 to 161 days and correlation was established between two different types of resistivity in different groups. Ratio of surface to bulk resistivity and corresponding resistance were calculated and compared with theoretical values at all ages starting from 7 to 161 days. It also highlights pattern of chronological development of surface and bulk electrical resistivity over a longer period of time and correlation of surface resistivity between 161 days with other time periods.

\section{Experimental Investigation}

\subsection{Materials and Mixture Proportions}

Thirty three different types of ternary and binary cementitious mixtures including the control mixture of $100 \%$ ordinary portland cement with a water/cementitious materials ratio of 0.44 were designed to give a wide range of values for this experimental program. This water/cementitious materials ratio is typical of exposed bridge deck and substructure concrete. All mixtures contained $335 \mathrm{~kg} / \mathrm{m}^{3}$ $\left(564 \mathrm{lbs} / \mathrm{yd}^{3}\right)$ of cementitious material with a coarse aggregate factor (CAF) of 0.67 . Limestone coarse aggregate of size $19 \mathrm{~mm}$ (3/4 inch) meeting ASTM C33 No. 67 gradation and ASTM C33 silica sand were used. All the SCMs were replaced by mass. Tests were performed on mixtures using:

- Type II-V cement (TII-V)

- Ground granulated blast furnace slag of grade 120 (G120S)

- Ground granulated blast furnace slag of grade 100 (G100S)

- Class C fly Ash (C)

- Class F fly Ash (F)

- Silica fume (SF)

- Metakaolin (M)

Due to sulfate attack problems in California, it is mandatory to use Type II-V cement instead of Type I cement. The selection of mixture design was based on concrete mixtures meeting basic technical properties and also representing a diverse range of solutions to long term durability. The basic mixture parameters were coded into the names of the mixtures with percentage of each cementitious material, e.g. 75TII-V/20F/5SF means $75 \%$ Type II-V Cement, $20 \%$ Class F fly ash and $5 \%$ Silica Fume. A high-range water reducing admixture (Glenium 7500) and an air entraining agent (MBVR AE90) were used to meet better workability and other durability performance specifications. All the mixtures were cast according to ASTM C192 practice and four cylinders $100 \times 200 \mathrm{~mm}(4 \times 8 \mathrm{in}$. $)$ were prepared for both bulk and surface electrical resistivity testing at all ages. The cylinders were demolded after $24 \pm 2 \mathrm{~h}$ and they were continuously cured in lime water tank. Electrical resistivity was measured on $7,14,28,56,91$ and 161 days.

\subsection{Measurement of Surface Electrical Resistivity}

Surface resistivity measurement was performed by commercially available 4 point Wenner probe surface resistivity (SR) meter, manufactured by Proceq. In this study, Florida testing method was used for electrical resistivity measurement on $7,14,28,56,91$ and 161 days for $100 \times 200 \mathrm{~mm}(4 \times 8$ in.) cylinders except the curing condition and the probe spacing. All the cylinders were cast and then demolded within $24 \pm 2 \mathrm{~h}$. After demolding, the cylinders were placed in lime water tank. A multiplier of 1.1 is used for electrical resistivity data as suggested by AASHTO TP-95 specification for lime water curing condition. All the cylinders were removed from lime water tank on the specified testing days and tested in saturated surface dry (SSD) condition at $23 \pm 2{ }^{\circ} \mathrm{C}$ by Resipod Wenner Probe meter. Readings were taken two times with 0,90, 180 and 270 degree angles of circular face of each concrete cylinder. The data in this research were collected using a probe spacing of $50 \mathrm{~mm}$ ( 2 inches), instead of $38 \mathrm{~mm}$ (1.5 inches) as recommended by FDOT. The probe spacing could not be changed as it came from the manufacturer with $50 \mathrm{~mm}$ (2 inches) spacing. The whole experimental process took less than half hour to complete. Four cylinders were tested for each concrete mixture and altogether 32 data points $(4 \times 8=32$ points $)$ were 
collected for each mixture for surface electrical resistivity. The equipment measures the current flowing between the outer electrodes and the potential difference between the two inner electrodes. Assuming that the concrete cylinder has homogeneous semi-infinite geometry (the dimensions of the element are large in comparison of the probe spacing), and the probe depth is far less than the probe spacing, the concrete cylinder resistivity $\rho$ can be computed as:

$$
\rho_{1}=2 \pi a \frac{V}{I}=2 \pi a R_{1}
$$

where $a$ is the probe spacing in $\mathrm{mm} ; V$ is the applied voltage in volt; $I$ is the current in ampere; and $R_{1}$ is the surface resistance in $\mathrm{KOhm}$.

\subsection{Measurement of Bulk Electrical Resistivity}

The Merlin conductivity tester was used to measure the bulk electrical conductivity, or its inverse, the bulk electrical resistivity, of water saturated concrete cylinders of $100 \times 200 \mathrm{~mm}(4 \times 8$ in $)$ in lime water tank. Bulk resistivity measurement was performed on the same cylinder sample as of surface electrical resistivity measurement. This test is also non-destructive and simple to perform. A test result was obtained within $2 \mathrm{~s}$, and sample preparation and testing altogether takes less than $30 \mathrm{~min}$. The conductivity of a saturated concrete specimen provides information on the resistance of the concrete to penetration of ionic species by the diffusion mechanism. The curing criteria and number of specimens were same as of surface electrical resistivity. Additionally, before testing, the tester verified with Merlin verification cylinder for rapid calibration purpose. A cylinder was placed on the support and two ends were wet with spraying bottle. This test method consists of applying a potential difference to the cylindrical specimen, thereby producing a current flow through the cylinder. The potential difference and resulting current can be utilized to obtain the electrical resistance. Two readings were obtained from data logger for each cylinder specimen by swapping the two end faces of a cylinder. From the measured current $I$ and voltage $V$, the bulk resistivity was calculated as follows:

$$
\rho_{2}=\frac{V}{I}\left(\frac{A}{L}\right)=R_{2}\left(\frac{A}{L}\right)
$$

where, $A$ is the surface area, $L$ is the length of the specimen and $R_{2}$ is the bulk resistance. Figure 1a and $\mathrm{b}$ shows experimental set up for Wenner 4-probe meter and Merlin conductivity tester.

For $100 \times 200 \mathrm{~mm}(4 \times 8$ inch $)$ cylinder, surface area $A=\pi \frac{d^{2}}{4}, d=100 \mathrm{~mm}$ (4 inches), $L=200 \mathrm{~mm}$ (8 inches), and probe spacing of $a=50 \mathrm{~mm}$ ( 2 inches). Finally, the ratio of theoretical surface and bulk resistance can be computed in Eq. (3).

$$
\frac{R_{1}}{R_{2}}=\left(\frac{\rho_{1}}{\rho_{2}}\right)(1 / 8)
$$

Morris et al. (1996) developed the geometry correction factor for specific cylinder sizes and the ratio of two different types of resistivity is computed as 2.63 . As a result, the ratio of theoretical surface and bulk resistance can be calculated as:

$$
\frac{R_{1}}{R_{2}}=2.63 / 8=0.33
$$

\section{Results and Discussions}

\subsection{Bulk and Surface Resistivity Data Analysis and Correlation}

Table 1 depicts classification of chloride ion permeability criteria of different concrete mixtures on the basis of surface electrical resistivity as suggested by FDOT specification. The correlation between bulk and SR on different days in different groups of mixtures is established and is shown in Figs. 2, 3, 4 and 5 . Average values of surface and bulk resistivity data from four cylinders for all mixtures (moderate to low permeability class) at all ages are provided in Tables 2 and 3. They show that both surface and bulk electrical resistivity increases over time and increment is more prominent at later ages in case of ternary based HPC mixtures compared to binary and ordinary portland cement mixtures. It is also evident that high percentage replacement of Class $\mathrm{C}$ fly ash did not perform well in binary or ternary blends. The possible reason is due to its incompatibility with Class F fly ash or other SCMs. Similar problem of Class $\mathrm{C}$ fly ash was studied by Rupnow et al. (2007). Average standard deviation of measurement of SR and bulk resistivity ranges between 0.4 to 6.6 and 0 to 3 from 7 to 161 days from all cementitious mixtures. It should be noted that mostly the standard deviation increases over time. It is believed that this may be due to slight variations in temperature or configuration of the sample affected by manual labor which may have occurred at the laboratory which could change differences overtime.

Figures 2, 3, 4 and 5 show the correlation between bulk and SR for different group of mixtures. It is observed that for most group of mixtures, the coefficient of determination values for linear trend line are higher than 0.8 and sometimes close to 1 except some silica fume mixtures at early ages where the coefficient becomes less than 0.80 . This proves that all binary and ternary mixtures are linearly well correlated in two different types of resistivity measurements at different test ages. In summary, it can be observed that the relationship between the bulk and SR of concrete is observed as linear and it follows same trend over time.

As mentioned above, the ratio of SR over bulk resistivity is computed as 2.63. In another word, the inverse ratio of bulk to SR is $1 / 2.63=0.38$. In Figs. 2, 3, 4 and 5, it can be observed that the slope of the linear trend line varies from 0.29 to 0.47 . It is to be also noted that the variation of slope values of all group mixtures decreases over time as it varies from 0.29 to 0.45 at 7 days and 0.32 to 0.44 at 161 days. It can be concluded that the surface and the bulk resistivity has strong linear correlation and the trend line slope found in all group mixtures again justifies the ratio between surface and bulk resistivity. 
(a)

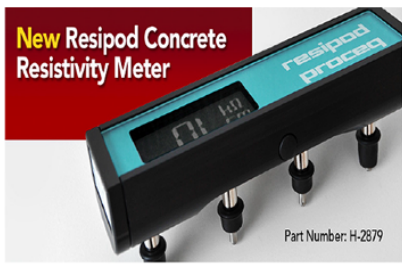

(b)

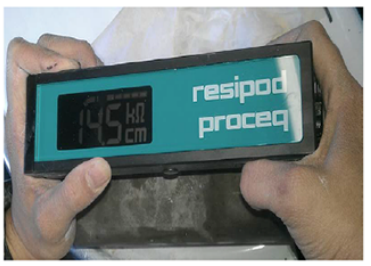

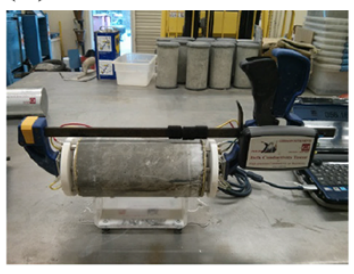

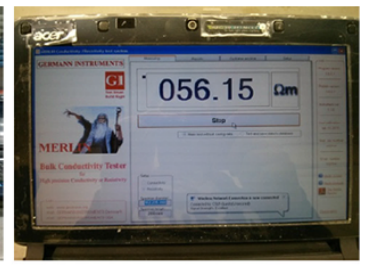

Fig. 1 Wenner 4-probe meter and Merlin conductivity tester. a Wenner 4-probe meter. b Merlin tester.

Table 1 Relationship between permeability class and surface resistivity (FDOT Standard 2004).

\begin{tabular}{c|c}
\hline Chloride ion permeability classification & Surface resistivity test 28 day test Kohm-cm \\
\hline High & $<12$ \\
\hline Moderate & $12-21$ \\
\hline Low & $21-37$ \\
\hline Very low & $37-254$ \\
\hline Negligible & $>254$ \\
\hline
\end{tabular}
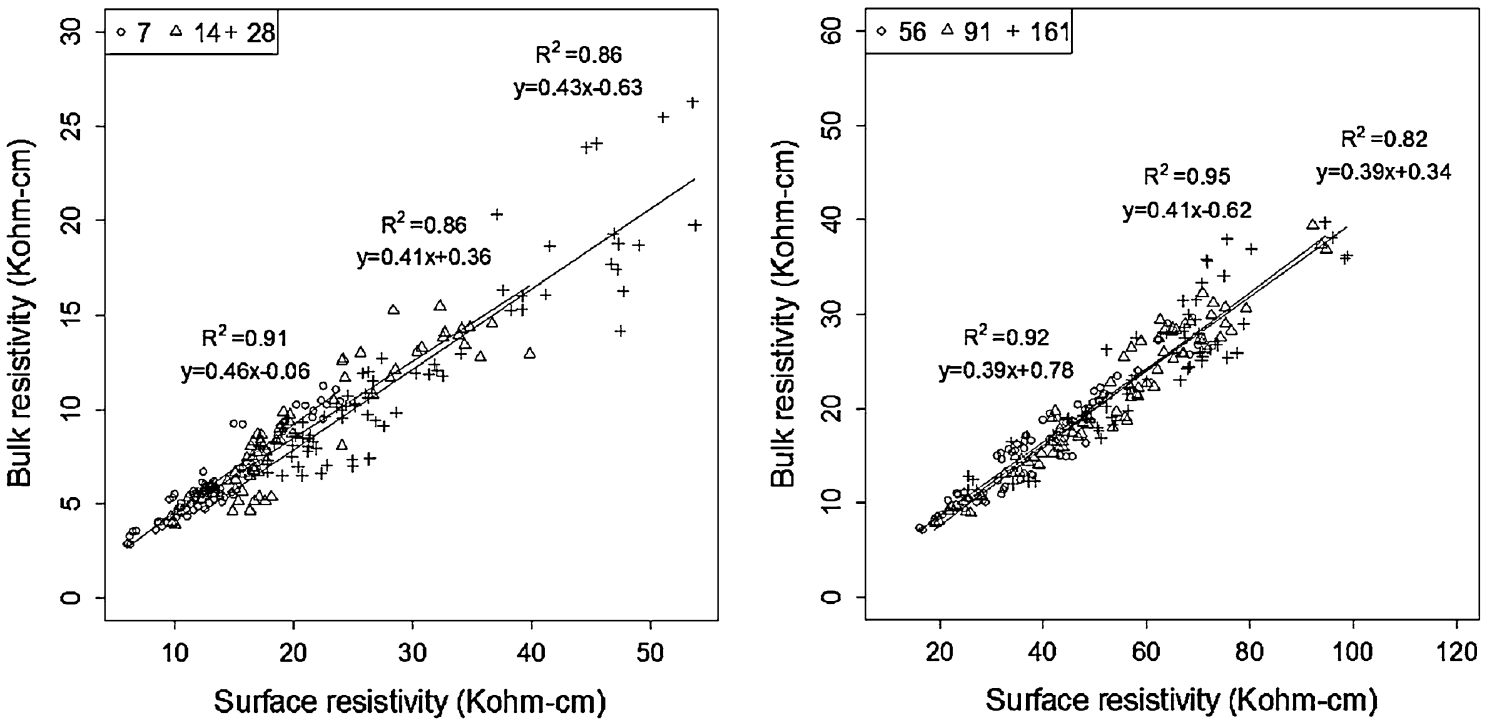

Fig. 2 Relationship between surface and bulk resistivity for fly ash mixtures.

\subsection{Comparison of Experimental Resistance and Resistivity Values}

Figure 6 shows distribution of ratio of experimental surface resistance to bulk resistance on different time periods. The box plot represents the range of average ratios between theoretical and experimental resistance those lay between the first quartile $\left(\mathrm{Q}_{1}\right)$ and the third quartile numbers $\left(\mathrm{Q}_{3}\right)$ for all cementitious mixtures. The horizontal line inside the box represents the median value of ratio. The vertical line below and above the box represent the remaining values of the ratios excluding the outlier. Outlier is shown as a symbol of (*) in their respective group obtained directly from statistical analysis software. An outlier is any data point that is more than 1.5 times the Inter Quartile Range $\left(\mathrm{IQR}=\mathrm{Q}_{3}-\mathrm{Q}_{1}\right)$ from either end of the box. It is evident that for all mixtures the ratio falls in between 0.29 to 0.36 (in between first and third quartile numbers) from 28 to 161 days. Some lower ratio in the range of $0.22-0.28$ is observed at early ages especially on 7 and 14 days due to inadequate development of SR compared to bulk resistivity. For this reason, at 14 days an outlier is observed for minimum values on the basis of statistical analysis. At 14 days, the minimum and maximum outliers are 0.21 and 0.41 respectively. Similarly, for some mixtures development of SR is significantly higher compared to bulk resistivity at 28, 56 and 91 days and this trend causes some outliers for maximum values of experimental ratio at those specific days. The maximum outliers at 28, 56 and 91 days are $0.51,0.41$ and 0.45 , respectively. However, the outliers did not exist consistently for a specific mixture except the mixture $60 \mathrm{TII}-\mathrm{V} / 35 \mathrm{G} 120 \mathrm{~S} / 5 \mathrm{SF}$ as the ratio remains high from 28 to 161 days. The possible reason for maximum outliers is the testing condition. In order to measure the bulk resistivity accurately, several requirements must be satisfied during testing. In the beginning of testing, 

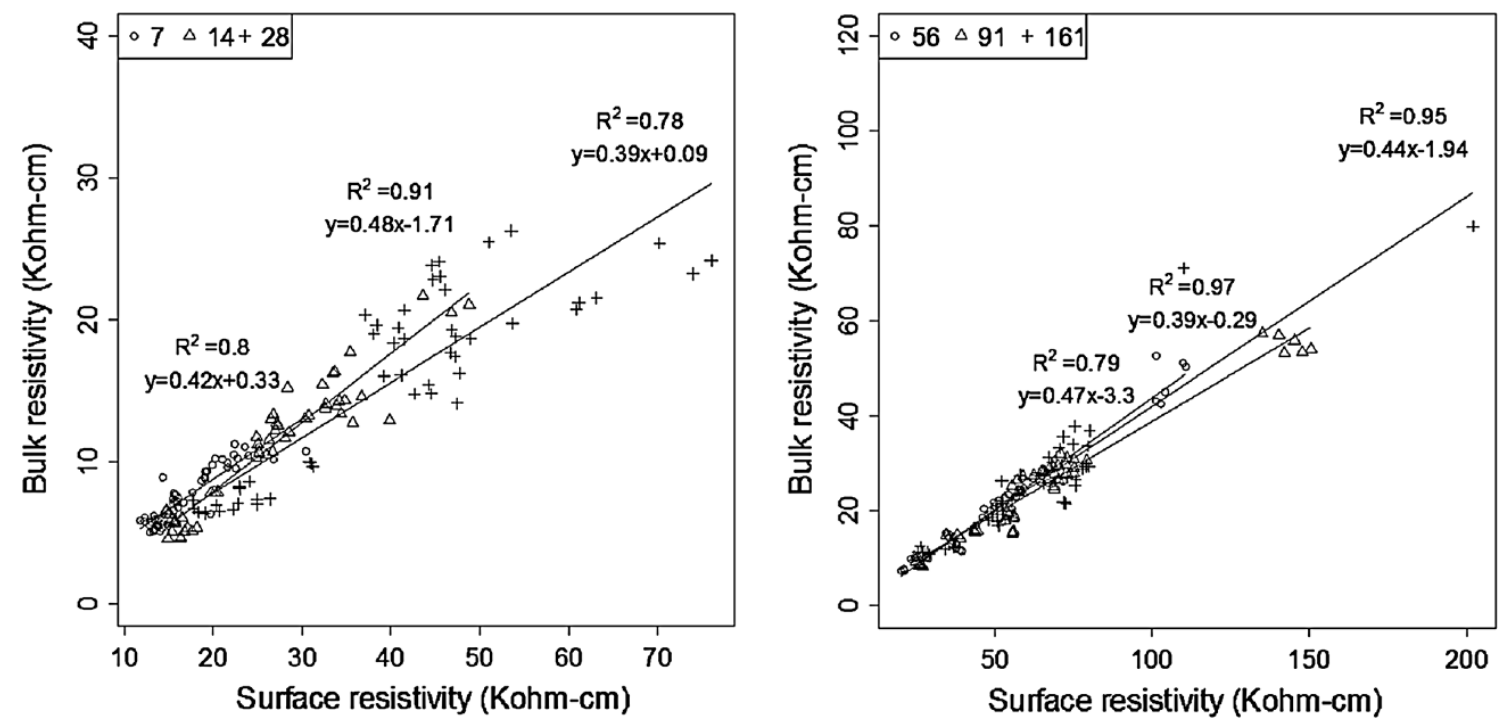

Fig. 3 Relationship between surface and bulk resistivity for slag mixtures.
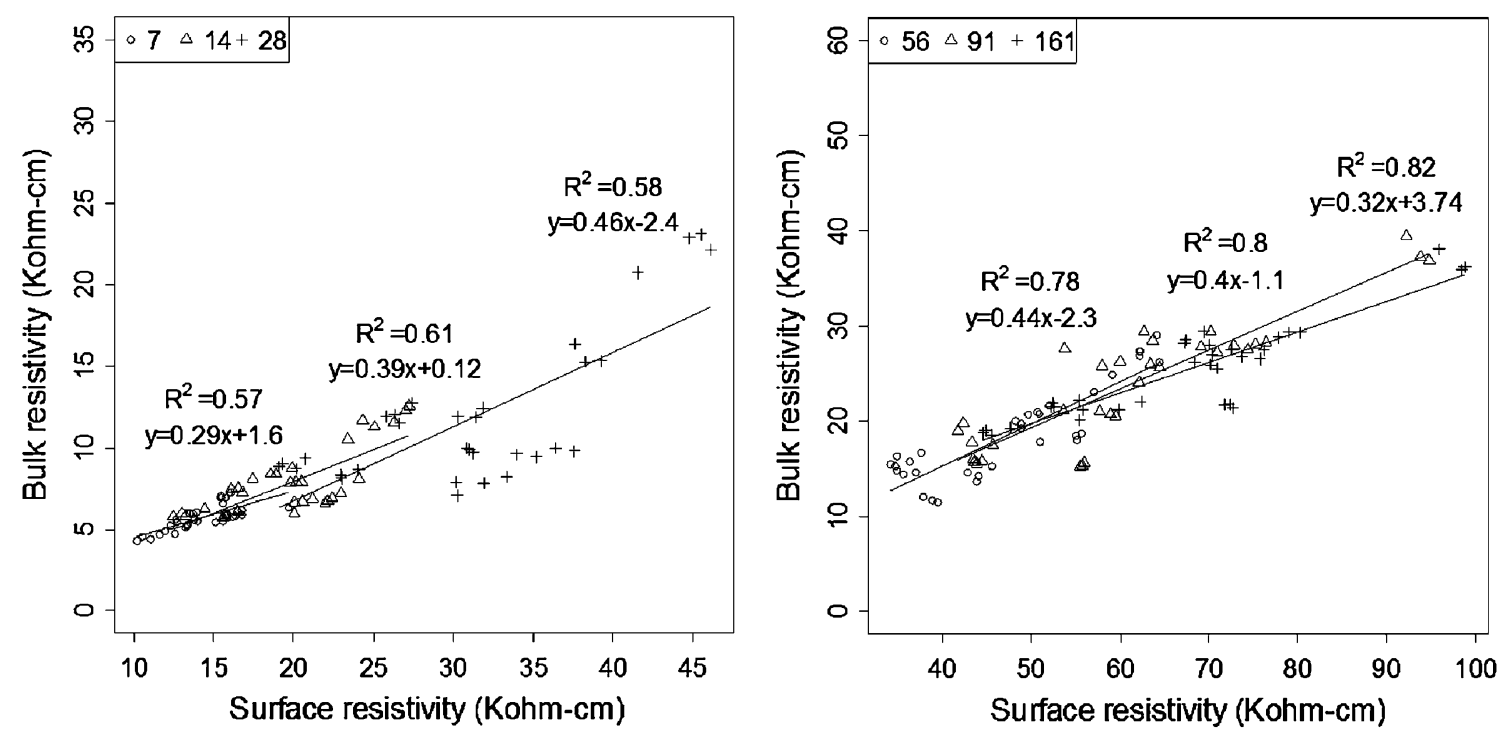

Fig. 4 Relationship between surface and bulk resistivity for silica fume mixtures.
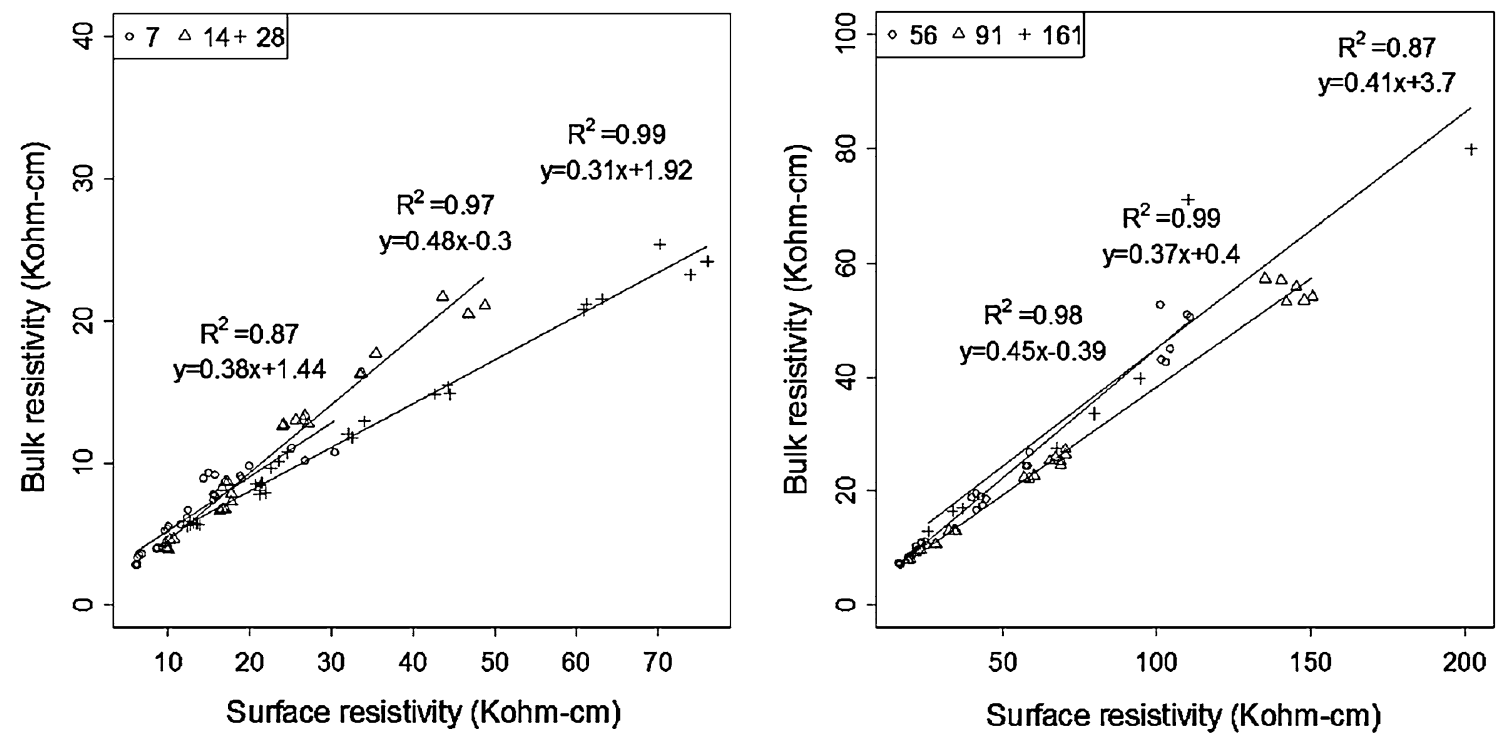

Fig. 5 Relationship between surface and bulk resistivity for metakaolin mixtures. 


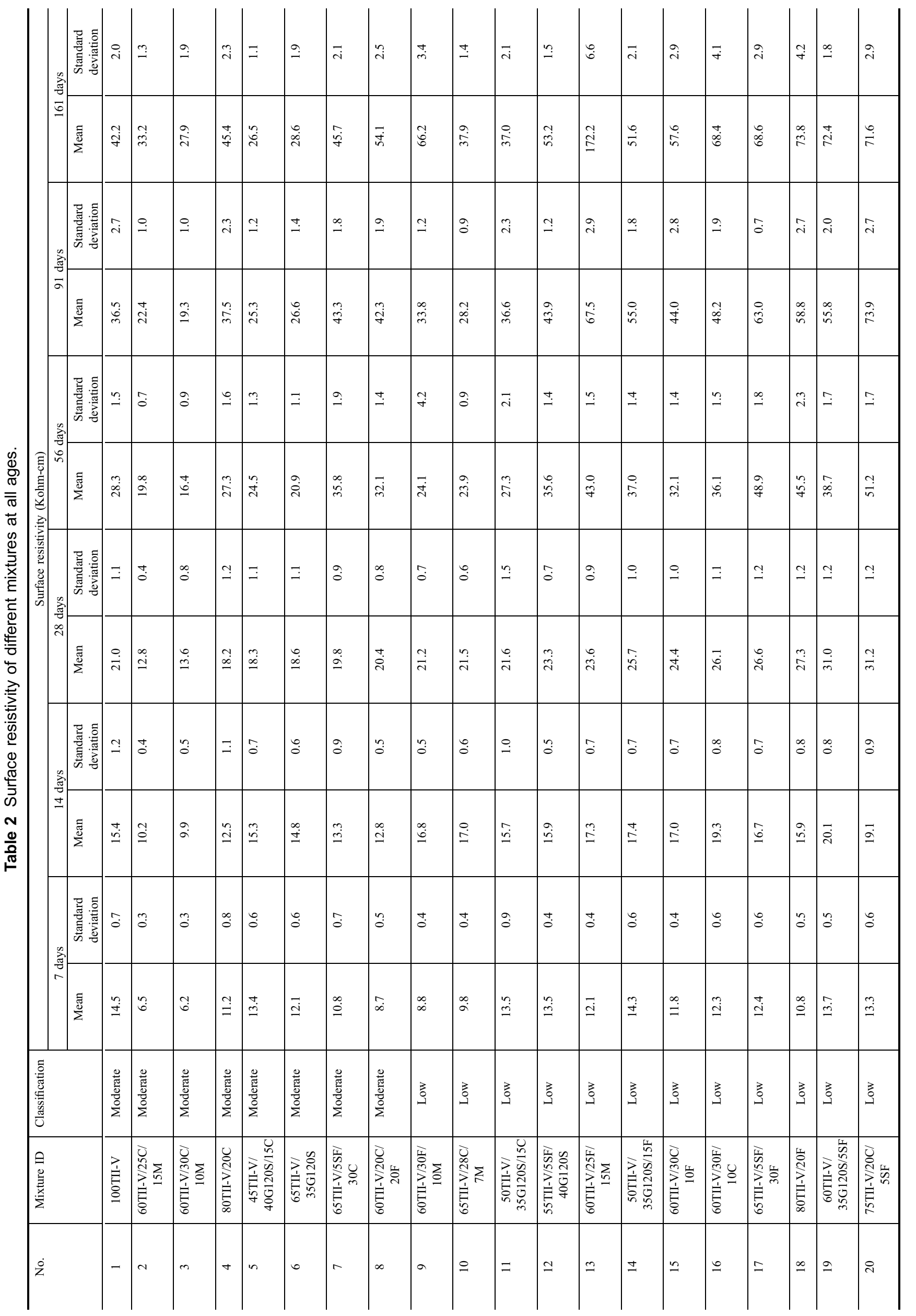




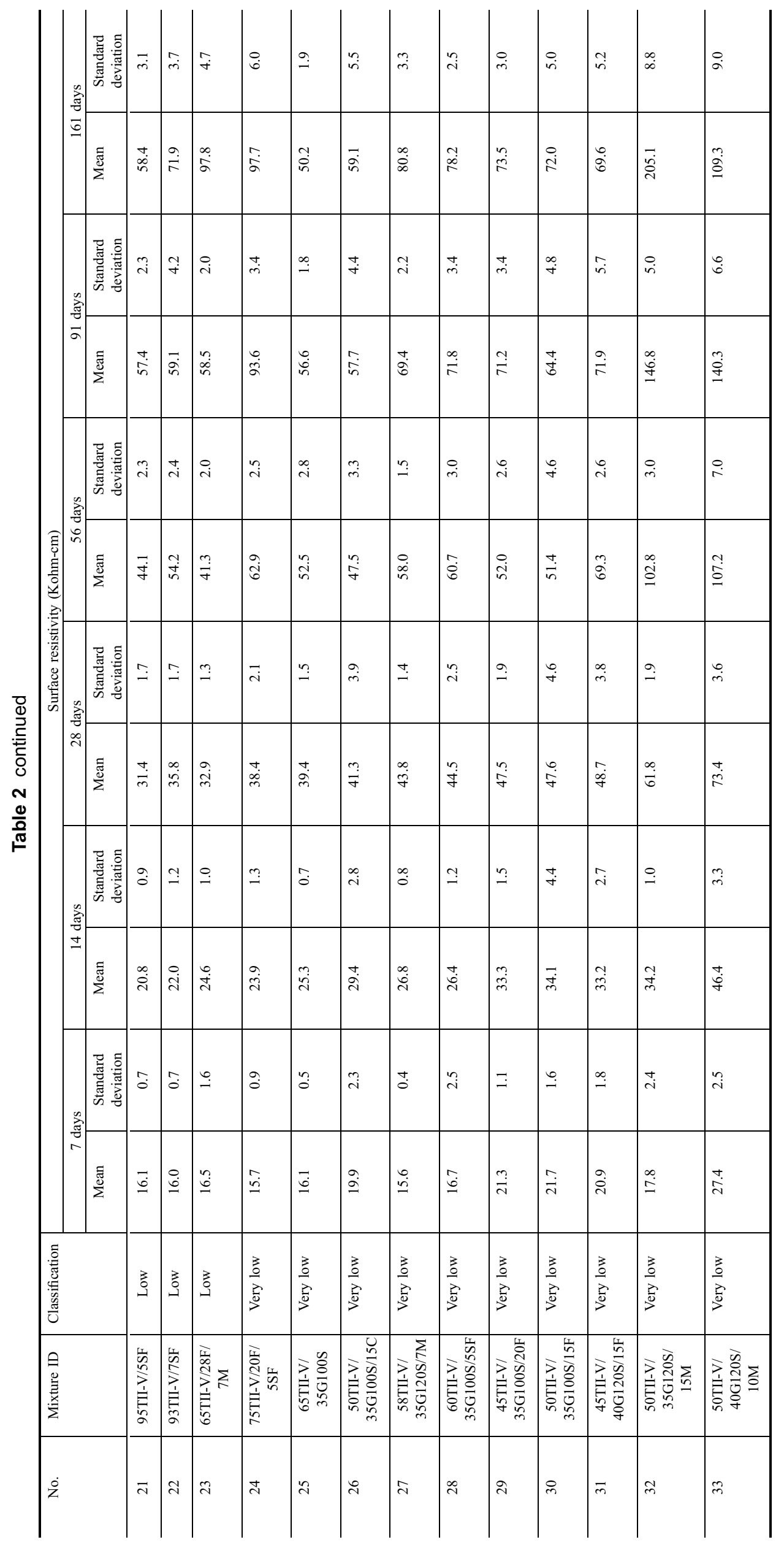




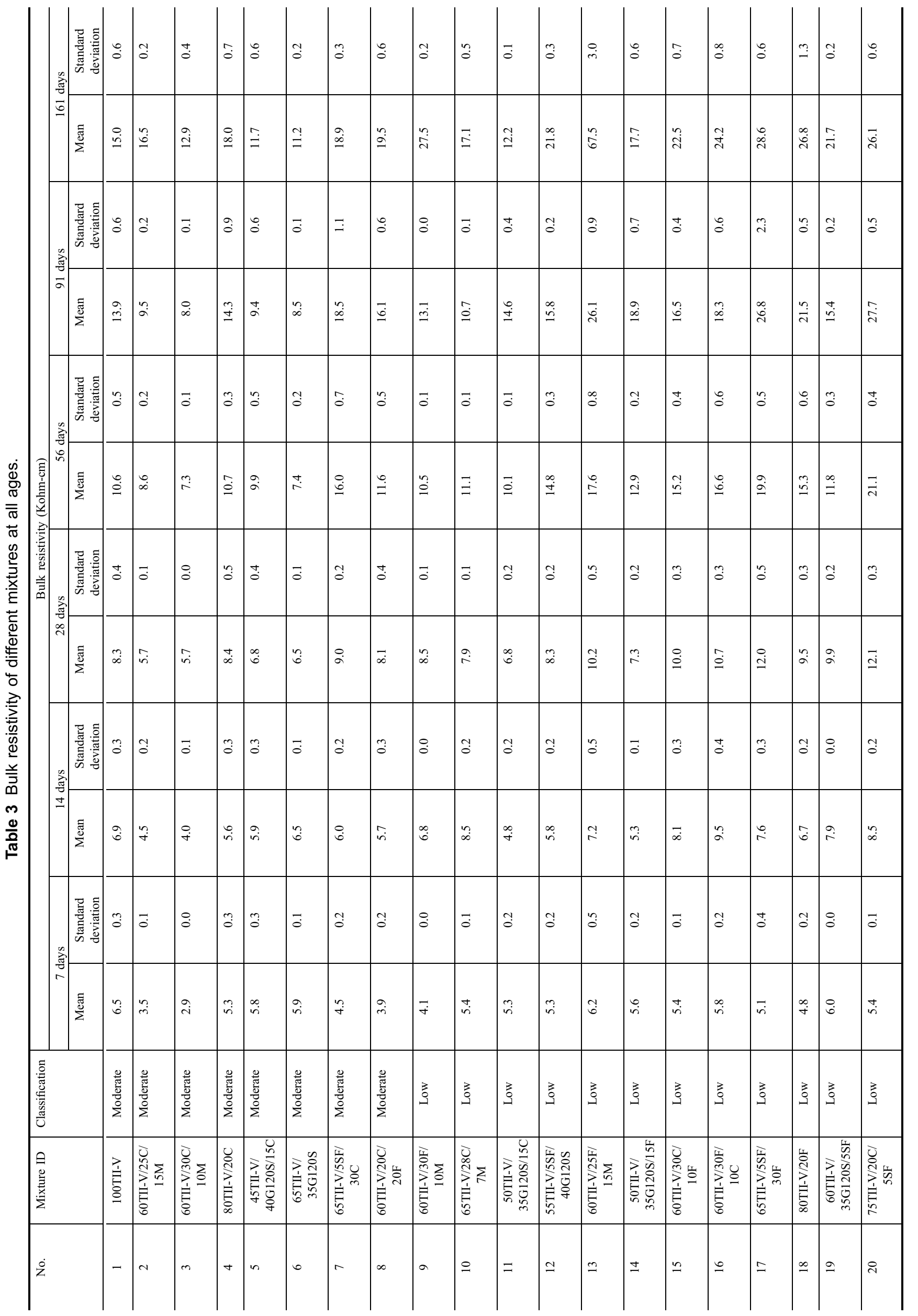




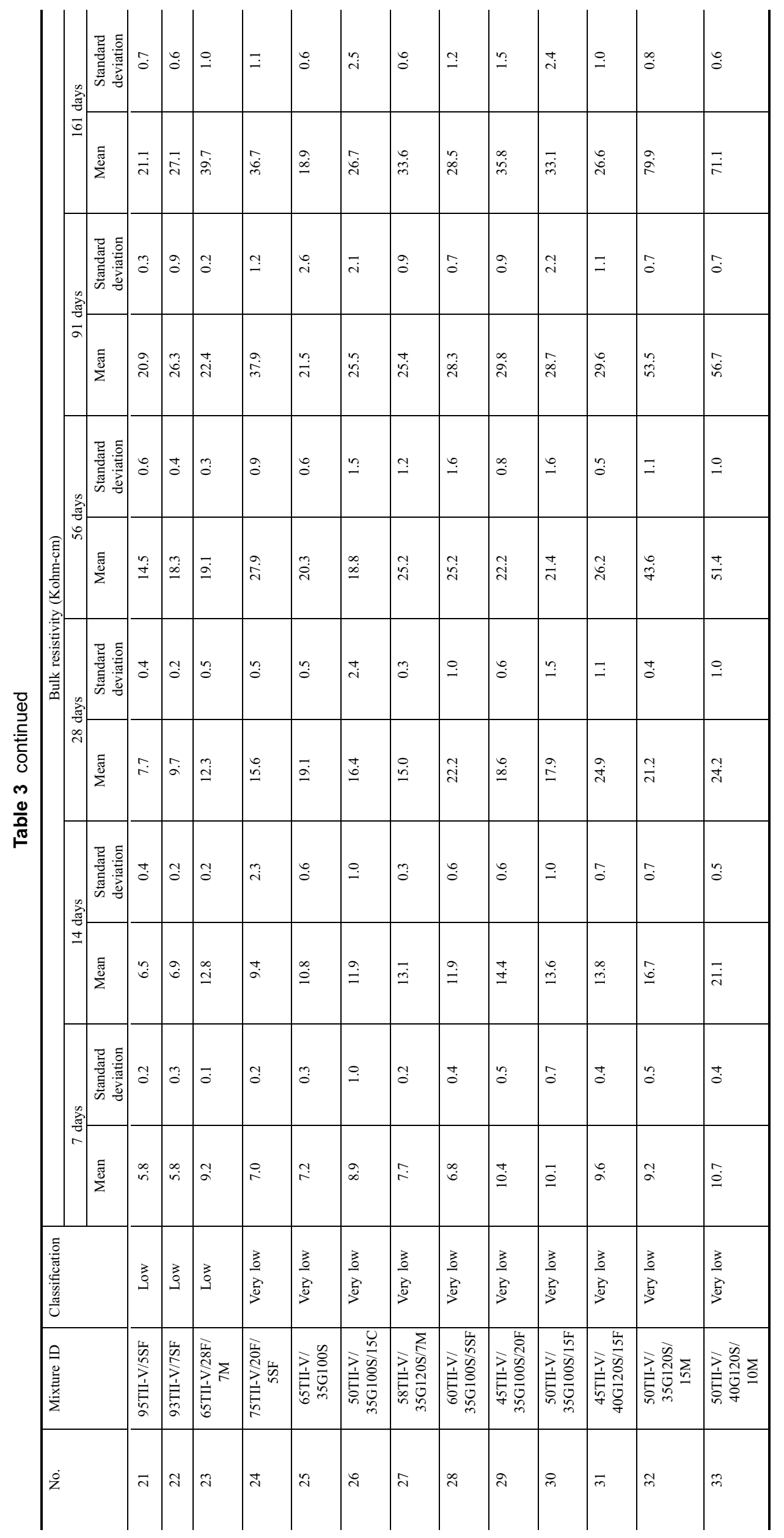




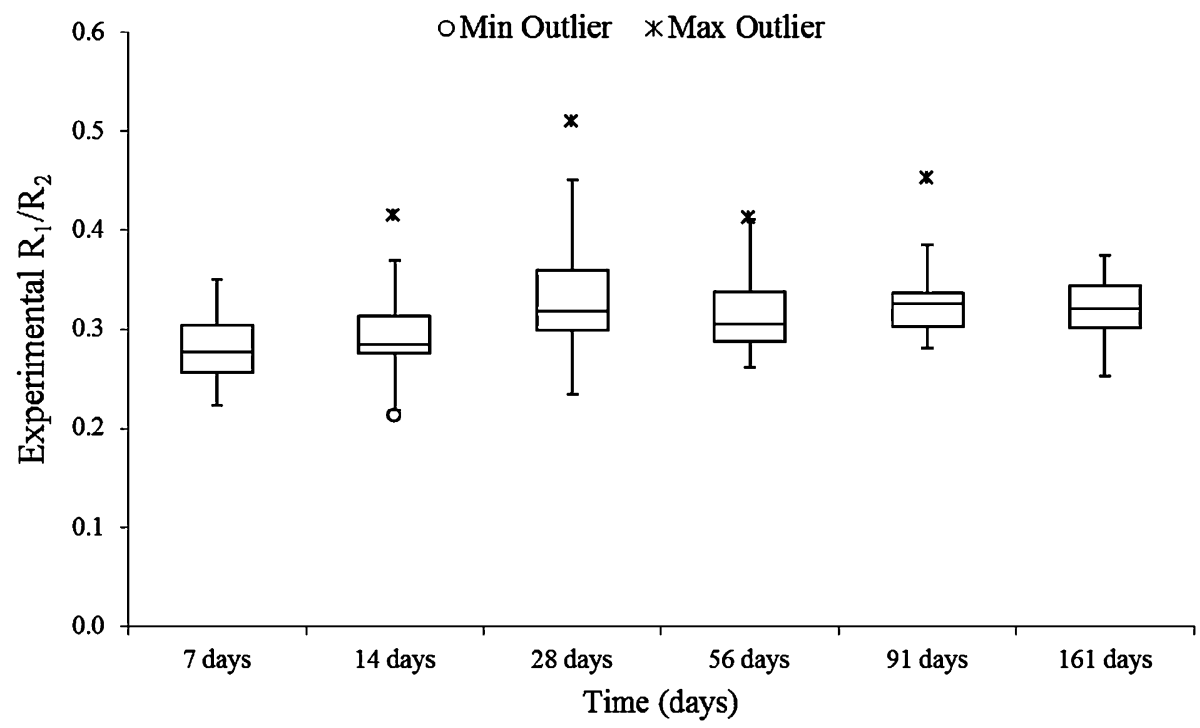

Fig. 6 Distribution of experimental surface vs. bulk resistance for all mixtures at all ages.

the specimen has to be totally water saturated and dry on the surface, which is sometimes hard to control in the laboratory environment. Additionally, the sponges soaked with water attached to both end of the specimen are sometimes stressed and water drains out into the surface of specimen and this causes variation of measurement of the bulk resistivity.

The IQR (IQR = Q3-Q1) for all days are small and varies from 0.03 to 0.06 . However, it can be observed that at 7 days, Q1 and Q3 values are 0.26 and 0.3 , respectively and it falls outside of the expected theoretical ratio value of 0.33 . Similarly, at 14 days, the values are 0.28 and 0.31 . Starting from 28 days, the expected value falls in the variation of Q1 and Q3 and the IQR decreases over time from 0.06 at 28 days to 0.03 at 91 days and 0.04 at 161 days. This is explained by the fact that the pozzolanic reactions of pozzolans or SCMs take longer time to complete.

Table 4 shows the ratio of surface vs. bulk resistivity at different test ages. It is evident from Table 4 that average ratio ranges in between 2.25 to 2.66 from 7 to 161 days. Overall, the ratio of surface vs. bulk resistivity is in good agreement with the theoretical geometric correction factor of 2.63 proposed by Morris et al.(1996), for a cylinder with a length of $200 \mathrm{~mm}$ ( 8 inches), diameter of $100 \mathrm{~mm}$ (4 inches) and probe spacing of $50 \mathrm{~mm}$ ( 2 inches). The average ratio is little smaller than 2.63 at early ages. It is also observed from Table 4 that theoretical geometric correction factor (2.63) closely matches with average ratios at 28,56 , 91 and 161 days for all cementitious mixtures. Recent study conducted by Spragg et al. (2012) also showed similar trend of results for comparison of surface and bulk resistivity at different ages. This relationship of ratio between surface and bulk resistivity actually represents an adjustment factor due to geometric size difference for measurement of electrical resistivity on different sizes of specimens. Sr measurement is an indirect way to obtain bulk resistivity using the ratio of surface vs. bulk resistivity namely the geometric shape factor. The numerical value of this ratio will help to obtain the resistivity of in situ semi-infinite bridge deck slab from the laboratory SR measurement of a cylindrical specimen.

\subsection{Correlation of Surface vs. Surface and Bulk vs. Bulk Resistivity at Different Days}

The correlations of resistivity of surface vs surface and bulk vs bulk between 161 days and that obtained at 28, 56, 91 days are shown in Figs. 7, 8 and 9 respectively. Two types of concrete mixtures are chosen for investigation: one group is for permeable and control mixtures and the other group is for various ternary based HPC mixtures. Polynomial equation was used for regression analysis in most cases as best correlation except SR vs SR for 28 and 161 days and 91 and 161 days. Power equation was used for those two specific cases as it provided better correlation coefficient. It is observed that as the time progresses towards 161 days, the correlation coefficient increases significantly for both permeable and HPC mixtures. The effect is more prominent in case of HPC mixtures as pozzolanic effect of SCMs takes significantly longer time to provide beneficial effect to improve pore structure. It needs to be remembered that all HPC mixtures achieved significant gain in electrical resistivity values over longer period of time. Implementation of these mixtures in future bridge decks can be effective before active corrosion starts in bridge decks and will reduce the corrosion potential remarkably. For this reason, long term monitoring of the electrical resistivity of the bridges is the key strategy of the success of this philosophy of extending the life of the infrastructure. Some HPC mixtures gained the electrical resistivity at later ages exceptionally well (more than $80 \mathrm{Kohm}-\mathrm{cm}$ ) compared to control and permeable mixtures. It is interesting to note that the correlation coefficient of bulk resistivity vs bulk resistivity was significantly higher than the correlation coefficient of SR vs SR at all ages for both permeable and HPC mixtures. This clarifies difference of precision levels between two experimental procedures. In addition, this correlation indicates chronological 
Table 4 Ratio of experimental surface and bulk resistivity on different time periods.

\begin{tabular}{|c|c|c|c|c|c|c|c|}
\hline \multirow[t]{2}{*}{ No. } & \multirow[t]{2}{*}{ Mixture ID } & 7 days & 14 days & 28 days & 56 days & 91 days & 161 days \\
\hline & & $\rho 1 / \rho 2$ & $\rho 1 / \rho 2$ & $\rho 1 / \rho 2$ & $\rho 1 / \rho 2$ & $\rho 1 / \rho 2$ & $\rho 1 / \rho 2$ \\
\hline 1 & $100 \mathrm{TII}-\mathrm{V}$ & 2.22 & 2.22 & 2.52 & 2.68 & 2.62 & 2.81 \\
\hline 2 & $\begin{array}{c}60 \mathrm{TII}-\mathrm{V} / 25 \mathrm{C} / \\
15 \mathrm{M}\end{array}$ & 1.86 & 2.24 & 2.24 & 2.30 & 2.37 & 2.02 \\
\hline 3 & $\begin{array}{c}60 \mathrm{TII}-\mathrm{V} / 30 \mathrm{C} / \\
10 \mathrm{M}\end{array}$ & 2.12 & 2.47 & 2.39 & 2.23 & 2.40 & 2.17 \\
\hline 4 & $80 \mathrm{TII}-\mathrm{V} / 20 \mathrm{C}$ & 2.11 & 2.24 & 2.16 & 2.55 & 2.62 & 2.53 \\
\hline 5 & $\begin{array}{c}45 \mathrm{TII}-\mathrm{V} / \\
40 \mathrm{G} 120 \mathrm{~S} / 15 \mathrm{C}\end{array}$ & 2.29 & 2.59 & 2.68 & 2.48 & 2.69 & 2.25 \\
\hline 6 & $\begin{array}{l}65 \mathrm{TII}-\mathrm{V} / \\
35 \mathrm{G} 120 \mathrm{~S}\end{array}$ & 2.05 & 2.27 & 2.88 & 2.81 & 3.15 & 2.56 \\
\hline 7 & $\begin{array}{c}65 \mathrm{TII}-\mathrm{V} / 5 \mathrm{SF} / \\
30 \mathrm{C}\end{array}$ & 2.43 & 2.23 & 2.21 & 2.23 & 2.34 & 2.41 \\
\hline 8 & $\begin{array}{c}60 \mathrm{TII}-\mathrm{V} / 20 \mathrm{C} / \\
20 \mathrm{~F}\end{array}$ & 2.23 & 2.24 & 2.51 & 2.76 & 2.63 & 2.78 \\
\hline 9 & $\begin{array}{c}60 \mathrm{TII}-\mathrm{V} / 30 \mathrm{~F} / \\
10 \mathrm{M}\end{array}$ & 2.17 & 2.49 & 2.48 & 2.31 & 2.58 & 2.40 \\
\hline 10 & $65 \mathrm{TII}-\mathrm{V} / 28 \mathrm{C} / 7 \mathrm{M}$ & 1.82 & 1.99 & 2.71 & 2.15 & 2.63 & 2.22 \\
\hline 11 & $\begin{array}{c}50 \mathrm{TII}-\mathrm{V} / \\
35 \mathrm{G} 120 \mathrm{~S} / 15 \mathrm{C}\end{array}$ & 2.56 & 3.31 & 3.17 & 2.70 & 2.51 & 3.03 \\
\hline 12 & $\begin{array}{c}55 \mathrm{TII}-\mathrm{V} / 5 \mathrm{SF} / \\
40 \mathrm{G} 120 \mathrm{~S}\end{array}$ & 2.55 & 2.72 & 2.79 & 2.40 & 2.78 & 2.44 \\
\hline 13 & $\begin{array}{c}60 \mathrm{TII}-\mathrm{V} / 25 \mathrm{~F} / \\
15 \mathrm{M}\end{array}$ & 1.96 & 2.39 & 2.32 & 2.44 & 2.58 & 2.55 \\
\hline 14 & $\begin{array}{c}50 \mathrm{TII}-\mathrm{V} / \\
35 \mathrm{G} 120 \mathrm{~S} / 15 \mathrm{~F}\end{array}$ & 2.56 & 3.31 & 3.52 & 2.86 & 2.92 & 2.92 \\
\hline 15 & $\begin{array}{c}60 \mathrm{TII}-\mathrm{V} / 30 \mathrm{C} / \\
10 \mathrm{~F}\end{array}$ & 2.18 & 2.09 & 2.44 & 2.11 & 2.68 & 2.57 \\
\hline 16 & $\begin{array}{c}60 \mathrm{TII}-\mathrm{V} / 30 \mathrm{~F} / \\
10 \mathrm{C}\end{array}$ & 2.12 & 2.04 & 2.45 & 2.17 & 2.64 & 2.83 \\
\hline 17 & $65 \mathrm{TII}-\mathrm{V} / 5 \mathrm{SF} / 30 \mathrm{~F}$ & 2.43 & 2.21 & 2.21 & 2.45 & 2.35 & 2.40 \\
\hline 18 & $80 \mathrm{TII}-\mathrm{V} / 20 \mathrm{~F}$ & 2.25 & 2.39 & 2.87 & 2.97 & 2.73 & 2.76 \\
\hline 19 & $\begin{array}{c}60 \mathrm{TII}-\mathrm{V} / \\
35 \mathrm{G} 120 \mathrm{~S} / 5 \mathrm{SF}\end{array}$ & 2.29 & 2.55 & 3.15 & 3.29 & 3.62 & 3.34 \\
\hline 20 & $\begin{array}{c}75 \mathrm{TII}-\mathrm{V} / 20 \mathrm{C} / \\
5 \mathrm{SF}\end{array}$ & 2.44 & 2.25 & 2.59 & 2.42 & 2.67 & 2.74 \\
\hline 21 & $95 \mathrm{TII}-\mathrm{V} / 5 \mathrm{SF}$ & 2.80 & 3.21 & 4.07 & 3.05 & 2.75 & 2.76 \\
\hline 22 & 93TII-V/7SF & 2.74 & 3.20 & 3.68 & 2.97 & 2.25 & 2.66 \\
\hline 23 & $65 \mathrm{TII}-\mathrm{V} / 28 \mathrm{~F} / 7 \mathrm{M}$ & 1.79 & 1.93 & 2.68 & 2.16 & 2.61 & 2.46 \\
\hline 24 & $75 \mathrm{TII}-\mathrm{V} / 20 \mathrm{~F} / 5 \mathrm{SF}$ & 2.24 & 2.55 & 2.46 & 2.25 & 2.47 & 2.66 \\
\hline 25 & $\begin{array}{l}65 \mathrm{TII}-\mathrm{V} / \\
35 \mathrm{G} 100 \mathrm{~S}\end{array}$ & 2.24 & 2.34 & 2.06 & 2.58 & 2.64 & 2.65 \\
\hline 26 & $\begin{array}{c}50 \mathrm{TII}-\mathrm{V} / \\
35 \mathrm{G} 100 \mathrm{~S} / 15 \mathrm{C}\end{array}$ & 2.24 & 2.47 & 2.52 & 2.53 & 2.26 & 2.22 \\
\hline 27 & $\begin{array}{c}58 \mathrm{TII}-\mathrm{V} / \\
35 \mathrm{G} 120 \mathrm{~S} / 7 \mathrm{M}\end{array}$ & 2.04 & 2.05 & 2.91 & 2.30 & 2.73 & 2.40 \\
\hline
\end{tabular}


Table 4 continued

\begin{tabular}{|c|c|c|c|c|c|c|c|}
\hline \multirow[t]{2}{*}{ No. } & \multirow[t]{2}{*}{ Mixture ID } & 7 days & 14 days & 28 days & 56 days & 91 days & 161 days \\
\hline & & $\rho 1 / \rho 2$ & $\rho 1 / \rho 2$ & $\rho 1 / \rho 2$ & $\rho 1 / \rho 2$ & $\rho 1 / \rho 2$ & $\rho 1 / \rho 2$ \\
\hline 28 & $\begin{array}{c}60 \mathrm{TII}-\mathrm{V} / \\
35 \mathrm{G} 100 \mathrm{~S} / 5 \mathrm{SF}\end{array}$ & 2.46 & 2.22 & 2.01 & 2.41 & 2.54 & 2.75 \\
\hline 29 & $\begin{array}{c}45 \mathrm{TII}-\mathrm{V} / \\
35 \mathrm{G} 100 \mathrm{~S} / 20 \mathrm{~F}\end{array}$ & 2.05 & 2.31 & 2.55 & 2.34 & 2.39 & 2.06 \\
\hline 30 & $\begin{array}{c}50 \mathrm{TII}-\mathrm{V} / \\
35 \mathrm{G} 100 \mathrm{~S} / 15 \mathrm{~F}\end{array}$ & 2.15 & 2.50 & 2.65 & 2.40 & 2.24 & 2.17 \\
\hline 31 & $\begin{array}{c}45 \mathrm{TII}-\mathrm{V} / \\
40 \mathrm{G} 120 \mathrm{~S} / 15 \mathrm{~F}\end{array}$ & 2.17 & 2.40 & 1.95 & 2.65 & 2.43 & 2.62 \\
\hline 32 & $\begin{array}{c}50 \mathrm{TII}-\mathrm{V} / \\
35 \mathrm{G} 120 \mathrm{~S} / 15 \mathrm{M}\end{array}$ & 1.93 & 2.05 & 2.92 & 2.36 & 2.74 & 2.57 \\
\hline 33 & $\begin{array}{c}50 \mathrm{TII}-\mathrm{V} / \\
40 \mathrm{G} 120 \mathrm{~S} / 10 \mathrm{M}\end{array}$ & 2.57 & 2.20 & 3.03 & 2.09 & 2.48 & 1.54 \\
\hline & & 2.24 & 2.41 & 2.66 & 2.50 & 2.61 & 2.52 \\
\hline
\end{tabular}
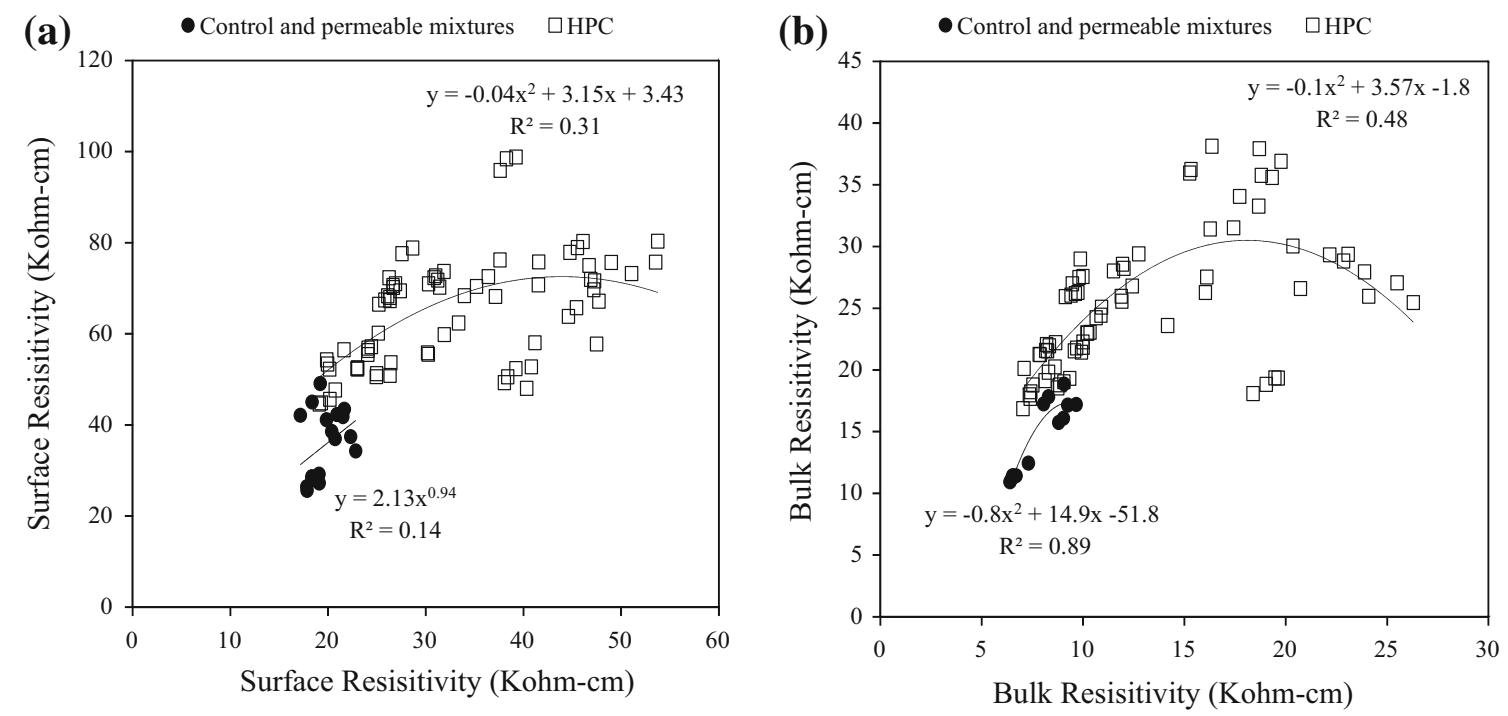

Fig. 7 Correlation of the resistivities between 28 and 161 days. a SR vs SR and b BR vs BR.

development of resistivity of HPC mixtures over an extended time period and differentiates from control and permeable mixtures in terms of accelerated rate of resistivity development at later ages. This is attributed to beneficial effect of high pozzolanic reactions of SCMs in ternary based HPC mixtures at later ages.

\section{Conclusions}

1. This comprehensive study presented here demonstrates the importance of variation and correlation of bulk and SR of different binary and ternary based HPC mixtures over longer period of time.

2. Both bulk and surface electrical resistivity are well correlated for different types of HPC and control mixtures over longer period of time ( 7 to 161 days).

3. Ratio of theoretical to experimental surface vs bulk resistance and ratio of surface and bulk resistivity are in good agreement for the application of geometric correction factor provided by the previous research study.

4. Most of the ternary and binary mixtures studied here have substantial influence to increase the surface and bulk electrical resistivity and improve long term resistance against corrosion over an extended period of time. The key reason is probably the densification of the matrix brought about by the pozzolanic reactions of pozzolans which try to close the pores and result in reducing permeability. Another possible reason is that these mix designs have different pore solution chemistries which might increase the bulk and SR.

5. Combination of Class $\mathrm{C}$ pozzolan with Class $\mathrm{F}$, silica fume, metakaolin and ordinary portland cement is not satisfactory in terms of development of surface and bulk resistivity. The possible reason is its incompatibility with other SCMs or chemical admixtures. It is also observed that metakaolin mixtures takes more than 

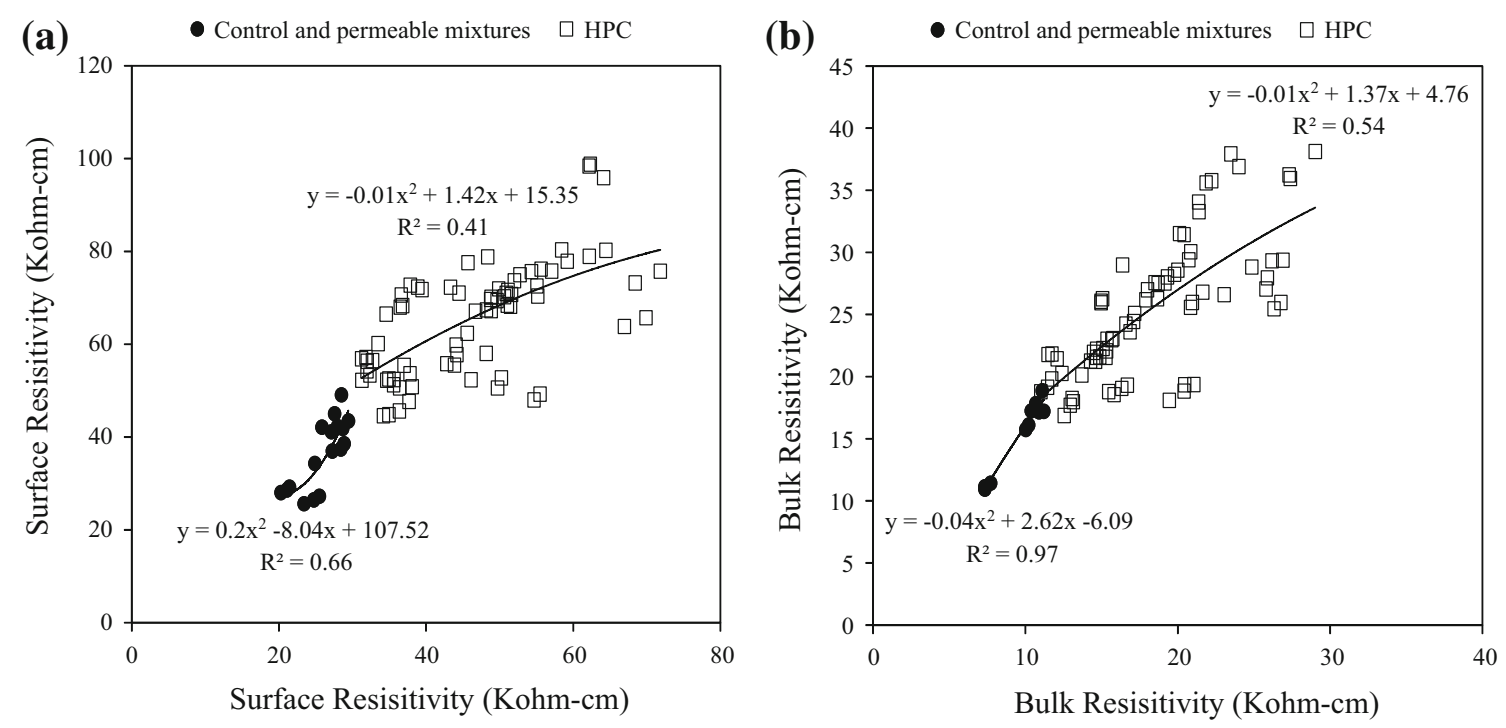

Fig. 8 Correlation of the resistivities between 56 and 161 days. a SR vs SR and b BR vs BR.
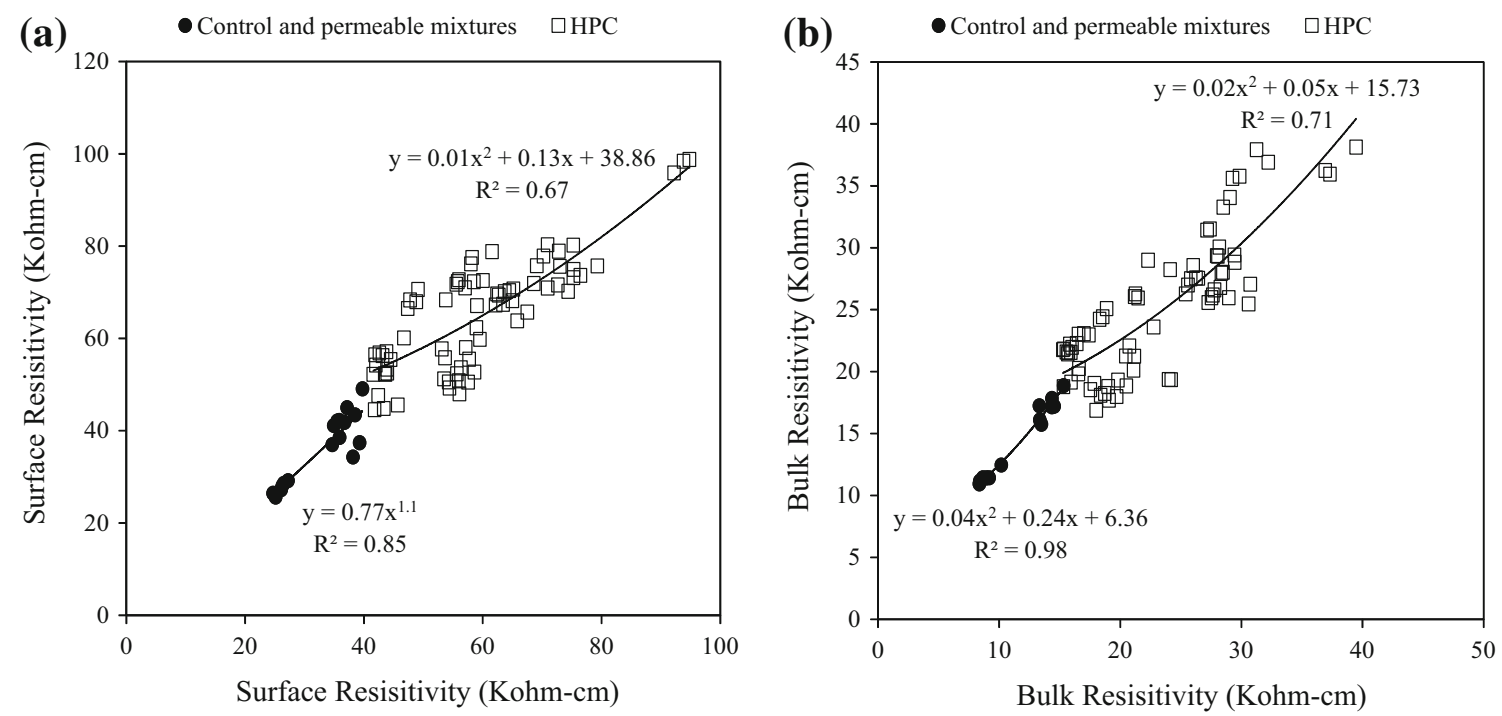

Fig. 9 Correlation of the resistivities between 91 and 161 days. a SR vs SR and b BR vs BR.

28 days to provide its superior beneficial effect by significant increment of bulk and surface electrical resistivity.

\section{Acknowledgments}

The authors would like to thank CSUF's grant office for the intramural grant to support this research. The authors also would like to thank BASF, Lehigh Cement Company, Mitsubishi Cement Corporation, Headwaters, and CMT Research Associates, LLC, Vulcan Materials Company, CalPortland Company for their generous donation of materials.

\section{Open Access}

This article is distributed under the terms of the Creative Commons Attribution License which permits any use, distribution, and reproduction in any medium, provided the original author(s) and the source are credited.

\section{References}

Christensen, B. J., Coverdale, R. T., Olson, R. A., Ford, S. J., Garboczi, E. J., Jennings, H. M., et al. (1994). Impedance spectroscopy of hydrating cement based materials: Measurement, interpretation, and application. Journal of American Ceramic Society, 77(11), 2789-2804.

Darren, T. Y., Lim, B., Sabet, D., Xu, D., \& Susanto, T. (2011). Evaluation of High Performance Concrete Using Electrical Resistivity Technique. In proceedings of 36th Conference on our World in Concrete \& Structures, Singapore, 14-16 August 2011.

FDOT Standard FM5-578. (2004). Florida method of test for concrete resistivity as an electrical indicator of its permeability. Florida Department of Transportation. 
Icenogle, P. J., \& Rupnow, T. D. (2012). Development of a precision statement for concrete surface resistivity. 92nd TRB Annual Meeting, Paper No. 12-1078, Washngton D.C., 23-26 Jan 2012.

Julio-Betancourt, G. A., \& Hooton, R. D. (2004). Study of the joule effect on rapid chloride permeability values and evaluation of related electrical properties of concretes. Cement and Concrete Research, 34(1), 1007-1015.

Katherine, K., Tinnea, J., Tinnea, R., Bellomio, S., Fanoni, M., Johnson, D., \& Towns, J. (2010). High Electrical Resistivity Concrete Mixture Design Using Supplementary Cementitious Materials. In Proceedings of Second International Conference on Sustainable Construction Materials and Technologies, Università Politecnica delle Marche, Ancona, Italy, 28-30 June 2010.

Kessler, R. J., Powers, R. F. \& Paredes, M. A. (2005). Resistivity measurements of water saturated concrete as an indicator of permeability, In Proceedings of NACE International Corrosion Conference. Houston, TX, Paper 5261, pp. $1-10$.

Marriaga, J. L., Claisse, P., \& Ganjian, E. (2010). Application of traditional techniques on chloride resistance assessment of GGBS concrete. In Proceedings of Second International Conference on Sustainable Construction Materials and Technologies, Università Politecnica delle Marche, Ancona, Italy, 28-30 June 2010.

Morris, W., Moreno, E. I., \& Sagües, A. A. (1996). Practical evaluation of resistivity of concrete in test cylinders using a Wenner array probe. Cement and Concrete Research, 26(12), 1779-1787.
Newlands, M. D., Jones, M. R., Kandasami, S., \& Harrison, T. A. (2008). Sensitivity of electrode contact solutions and contact pressure in assessing electrical resistivity of concrete. Journal of Materials Structures, 41(5), 621-632.

Paredes, M., Jackson, N. M., Safty, A. E., Dryden, J., Joson, J., Lerma, H., et al. (2012). Precision statements for the surface resistivity of water cured concrete cylinders in the laboratory. Advances in Civil Engineering Materials, 1(1), $1-23$.

Polder, R. B., Andrade, C., Elsener, B., Vennesland, Ø., Gulikers, J., Weidert, R., et al. (2004). Test methods for on-site measurement of resistivity of concrete. Materials and Structures, 33(10), 603-611.

Rupnow, T. D., Schaefer, V. R., Wang, K., \& Tikalsky, P. J. (2007). Effects of different air entraining agents (AEA), supplementary cementitious materials (SCM), and water reducing agent (WR) on the air void structure of fresh mortar, International Conference on Optimizing Paving Concrete Mixtures and Accelerated Concrete Pavement Construction and Rehabilitation, FHWA/ACI/ACPA, Nov 6-9, 2007.

Spragg, R. P., Castro, J., Nantung, T., Paredes, M., \& Weiss, J. (2012). Variability analysis of the bulk resistivity measured using concrete cylinders. Advances in Civil Engineering Materials, 1(1), 1-17.

Tikalsky, P., Taylor, P., Hanson, S., \& Ghosh, P. (2011). Development of performance properties 1 of ternary mixtures: Laboratory study on concrete. Ames, IA: Iowa State University. 